\title{
Recuperação de solos degradados na exploração mineral de cassiterita: biomassa microbiana e atividade da desidrogenase
}

\author{
Regina M. Longo ( $\left.{ }^{*}\right)$; Admilson Írio Ribeiro ( $\left.{ }^{2}\right)$; Wanderley José de Melo $\left({ }^{3}\right)$ \\ (') Faculdade de Engenharia Ambiental - PUC, Campinas (SP).E-mail: rmlongo@uol.com.br(*) Autora correspondente. \\ (2) Faculdade de Engenharia Ambiental - UNESP, Sorocaba (SP). E-mail: admilson.ribeiro@uol.com.br \\ (3) Faculdade de Ciências Agronômicas e Veterinárias - UNESP, Via de acesso Prof. Paulo Donato Castellane, Km 5, 14884-900 \\ Jaboticabal (SP). E-mail: wjmelo@fcav.unesp.br
}

Recebido: 10/mai./2010; Aceito: 11/jun./2010

\begin{abstract}
Resumo
A avaliação da qualidade ambiental assume grande importância em programas de recuperação de áreas degradadas, razão pela qual se faz necessário o desenvolvimento de sistemas quantitativos, com base em combinação de indicadores que meIhor representem as condições de degradação ou recuperação em curso. O presente trabalho utiliza-se de parâmetros biológicos do solo como a biomassa microbiana e a atividade de desidrogenase, além da análise do material vegetal, para verificar a influência do plantio sucessivo de leguminosas em um solo minerado em processo de recuperação. A atividade microbiana foi determinada a partir da quantificação do carbono e o nitrogênio da biomassa microbiana (BMC e BMN respectivamente), da atividade da desidrogenase e da hidrólise do FDA avaliadas em uma área de piso de lavra após um, dois e três anos de plantio consecutivos de leguminosas e de uma área de deposição de rejeito após um ano de plantio de um mistura de leguminosas: feijão guandu, mucuna preta e crotalária juncea, comparados com o solo sob mata e com áreas sem plantio. O uso dos indicadores biológicos: biomassa microbiana e atividade de desidrogenase, e da análise do material vegetal na avaliação das técnicas e estratégias de recuperação adotadas revelaram que o plantio de leguminosas e sua posterior incorporação vêm promovendo alterações graduais positivas no solo degradado, principalmente em relação à BMC em áreas após o plantio consecutivo de três anos de leguminosas.
\end{abstract}

Palavras-chave: adubação verde, recuperação de solos degradados, atividade enzimática.

\section{Recovery of degraded soils in the tin mineral exploitation: microbian biomass and dehydrogenase activity}

\begin{abstract}
The evaluation of the environmental quality assumes great importance in recovery programs of degraded areas, which makes necessary the development of quantitative systems based on combinations of indicators that best represent the degradation or the ongoing recovery conditions. This work uses soil biological parameters, such as microbian biomass and dehydrogenase activity, in addition to the analysis of the plant material to verify the influence of the successive planting of legumes in a mined soil undergoing recovery. The microbian activity was determined through the quantification of the microbian biomass' carbon and nitrogen (BMC e BMN), the dehydrogenase activity and FDA hydrolysis, evaluated in a mine pit area after one, two and three years of consecutive planting of legumes, and in a tailing area after one year of planting a mixture of legumes (pigeon peas, velvet beans and sunn hemp). Those areas were compared to forest soil and areas with no planting. The use of biological indicators (microbian biomass and dehydrogenase activity) and the analysis of plant material in the evaluation of the adopted techniques and strategies revealed that the planting of legumes and its further incorporation promoted positive and gradual modifications in the degraded soil, mainly in the BMC in areas after the consecutive planting of legumes over the course of three years.
\end{abstract}

Key words: green manure, recovery of degraded soils, enzymatic activities. 


\section{INTRODUÇÃO}

A análise de indicadores bioquímicos e microbiológicos em solos degradados ou em processo de recuperaçáo é de suma importância quando se deseja obter informaçóes sobre a qualidade do ambiente e da sustentabilidade do ecossistema nos tratamentos indicados. Além de constituírem informações complementares na avaliação qualititativa dos solos, os indicadores microbiológicos têm sido frequentemente sugeridos como sensíveis aos impactos causados pelo manejo do solo, quando comparado àqueles de caráter físico ou químico (TRASAR-CEPEDA et al., 1998; Leirós et al., 2000; BEnding et al., 2004)

A atividade de explotação mineral pode proporcionar impactos diretos e indiretos de diferentes naturezas sobre a área em exploração e seu entorno. Os impactos sobre o solo, a vegetação e os recursos hídricos presentes no sistema são observadps na forma de alteraçôes estéticas, físicas, químicas e biológicas, dependendo, logicamente, das características da geologia, vegetação, relevo e solo locais, bem como do tipo de lavra e minério a ser extraído.

Modelos de recuperação de solos degradados devem se basear em tecnologias que sejam capazes de melhorálo por meio do aporte de matéria orgânica com baixa relaçáo C/N (Franco et al., 1992) permitindo o restabelecimento da vida no solo. A biomassa microbiana do solo pode ser bom indicador de recuperaçáo de solos postos em recuperação, pois atua como agente da transformação bioquímica dos compostos orgânicos, sendo também um reservatório de N, P e S (Wardle, 1992). O significado ecológico de biomassa tem como destaques, além de armazenador de nutrientes, o de servir como indicador rápido de mudanças no solo, quando o material orgânico é incorporado denotando a sensibilidade da microbiota a interferências no sistema (GRISI, 1996). A medição do carbono, particularmente, é útil à compreensão sobre a ciclagem da matéria orgânica e bom indicador da qualidade do solo, podendo atuar como fonte e dreno de nutrientes através da mineralização e imobilização. O carbono da biomassa (BMC) geralmente compreende de $1 \%$ a $4 \%$ do carbono orgânico do solo, havendo uma correlação linear entre ambos (JENKINSON e LADD, 1981). O BMC deve ser analisado juntamente com um indicador da atividade, em face da extrema heterogeneidade do ambiente natural da microbiota e da sua biodiversidade, sendo considerada mais sensível às mudanças na qualidade do solo do que características químicas como carbono e/ou nitrogênio total orgânico (Anderson e Domsch, 1993).

Independentemente da finalidade a que se propóe um programa de recuperaçáo, as açóes recuperadoras pressupóem o uso de medidas de proteçáo do solo, dentre as quais a formação de uma vegetação de cobertura tem sido imprescindível. Devido à grande dificuldade no estabelecimento da vegetação inicial deverão ser utilizadas espécies rústicas e agressivas o bastante para se desenvolverem em ambientes hostis e, preferencialmente, com características que contribuam para o reequilíbrio e a estabilização do ecossistema, propiciando a atuação dos mecanismos e dos processos naturais de colonização e integração da flora e fauna (Resende e Kondo, 2001).

A vegetação influencia diferentemente a biomassa microbiana, e por esse motivo, sua eliminação ocasiona uma drástica queda da biomassa carbono, como revelam estudos envolvendo desmatamentos (PFenning et al. 1992). As plantas leguminosas, devido à ampla diversidade de espécies, versatilidade de usos potenciais e ao seu papel na dinâmica dos ecossistemas, especialmente no tocante ao suprimento e à ciclagem do nitrogênio, proporcionam enorme potencial na reabilitação de áreas degradadas, razão pela qual vêm sendo sistematicamente inseridos em programas dessa natureza.

Este trabalho teve por objetivo avaliar as alteraçōes promovidas em solos/substratos degradados pela mineração de cassiterita após o plantio consecutivo de adubação verde como técnica de revegetação, analisando a biomassa microbiana, atividade da desidrogenase, hidrólise do diacetato de fluoresceína (FDA) e análise química e massa de matéria seca das espécies introduzidas.

\section{MATERIAL E MÉTODOS}

As amostras de solo e planta foram coletadas em experimento montado na Floresta Nacional do Jamari (FLONA), administrada pelo Instituto Brasileiro do Meio Ambiente e Recursos Minerais Renováveis - IBAMA, estando esta situada a $90 \mathrm{~km}$ da cidade de Porto Velho (RO), no município de Itapuã d'Oeste (Figura 1).

A FLONA compóes-se de uma área de aproximadamente 220.000 ha, das quais $90 \%$ estão cobertas por Floresta Tropical Aberta (RADAMBRASIL, 1978). Nas cercanias da área selecionada para estudo predominam os solos da classe taxonômica Latossolo Vermelho-Amarelo distroférrico e Latossolo Amarelo distroférrico (EMBRAPA, 1999), e o ensaio foi realizado em Latossolo Vermelho-Amarelo. O clima da regiáo é quente e úmido, com temperaturas médias de $24^{\circ} \mathrm{C}$, precipitaçáo pluvial anual de $2550 \mathrm{~mm}$, com máximos de dezembro a março. A umidade relativa fica em torno de $80 \%$ a $85 \%$, havendo uma estação seca bem definida, com período mais crítico de julho a agosto.

As diferentes atividades e processos envolvidos na mineração de cassiterita que ocorrem no interior da FLONA desde a década de 70 resultam em substratos com características que decorrem do tipo e da composiçáo da rocha matriz, dos processos de degradação, da forma e do tempo de exposição do material remanescente. Dessa forma, torna-se necessário uma caracterização dos substratos onde o ensaio foi estabelecido. 
Piso de lavra (PL): A abertura de cavas para a exploração de cassiterita exige a exposição de encostas, do subsolo e algumas vezes da própria rocha. Na medida em que a cava se aprofunda, exige-se maior exposição de encostas e maior área exposta de subsolo. O material exposto e onde deverá se proceder a recuperação possui características distintas do solo original, em virtude do tipo de material, do processo de abertura da cava, da necessidade de vias de acesso e do volume do minério explorado.

Rejeito seco (RS): localiza-se próximo à barragem de contenção de rejeitos, possui granulometria com partículas maiores, principalmente areia, ausência de estruturação, baixa ou baixíssima fertilidade natural e algumas vezes dificuldades de mecanização, pois o material é muito solto. Nota-se também, pela própria característica arenosa, uma alta permeabilidade, o que torna o material com baixa capacidade de retenção de água.

Para este trabalho, foram plantadas três espécies de leguminosas com bom desenvolvimento e boa produção de matéria seca em sistemas degradados: Crotalaria juncea (crotalária), Cajanus cajam (feijão guandu) e Mucuna aterrima (mucuna preta). Estas espécies foram plantadas juntas, em uma mistura de sementes nas duas áreas de estudo (Wutke, 1993).

Antes do primeiro plantio foi realizada uma escarificaçấo, seguida da aplicaçáo de 2 ton.ha ${ }^{-1}$ de calcário dolomítico e posterior gradeação. No plantio, foram utilizados $450 \mathrm{~kg} \mathrm{ha}^{-1}$ de NPK 10-10-10 e $80 \mathrm{~kg} \mathrm{ha}^{-1}$ de sementes de leguminosas. $\mathrm{O}$ experimento foi instalado em um delineamento inteiramente casualizado, com sete tratamentos e quatro repetiçóes. Os tratamentos foram assim designados:

T1: piso de lavra com plantio de um ano de leguminosas, com escarificação, aplicação de calcário e adubação química;

T2: piso de lavra com plantio de leguminosas, em dois anos consecutivos, com escarificação, aplicação de calcário e dubação química;

T3: piso de lavra com plantio de leguminosas em três anos consecutivos, com escarificação, aplicação de calcário e adubação química;

T4: rejeito com plantio de um ano de leguminosas, sem escarificação, com aplicação de calcário e adubação química;

T5: solo de mata, sem plantio de leguminosas, sem escarificação, aplicação de calcário e adubação química;

T6: piso de lavra sem plantio de leguminosas, sem escarificação, aplicação de calcário e adubação química;

T7: rejeito sem plantio de leguminosas, escarificação, aplicação de calcário e adubação química;

As amostras de solo foram coletadas superficialmente na camada de 0-0,20 m com o auxílio de um trado. Em cada tratamento foram coletadas quatro amostras compostas. As amostras para a análise biológica foram acondicionadas em gelo até o momento das análises.
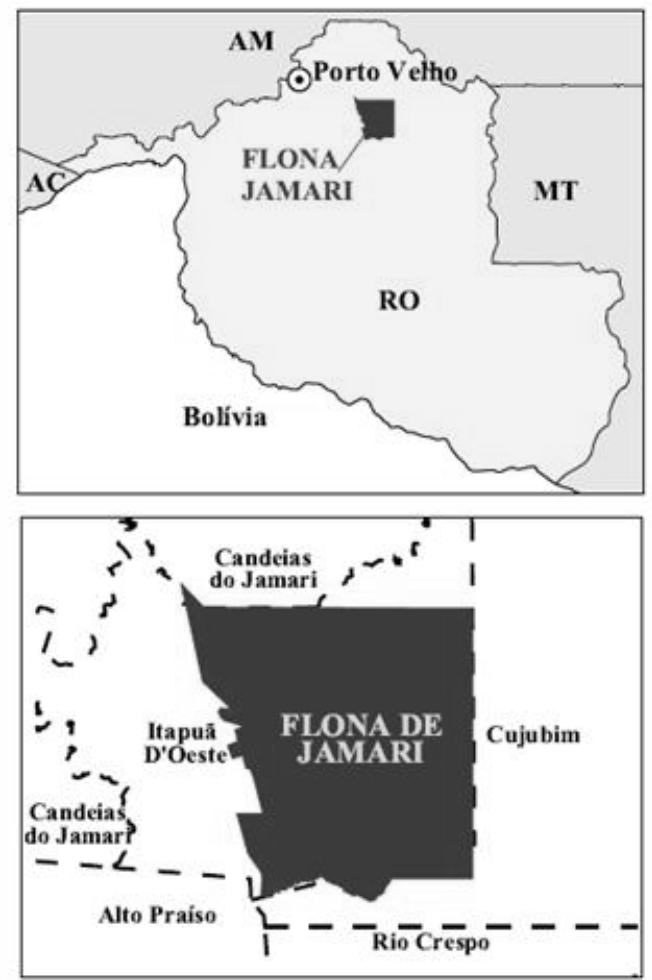

Fonte: IBAMA

Figura 1. Localização da FLONA do Jamari (RO).

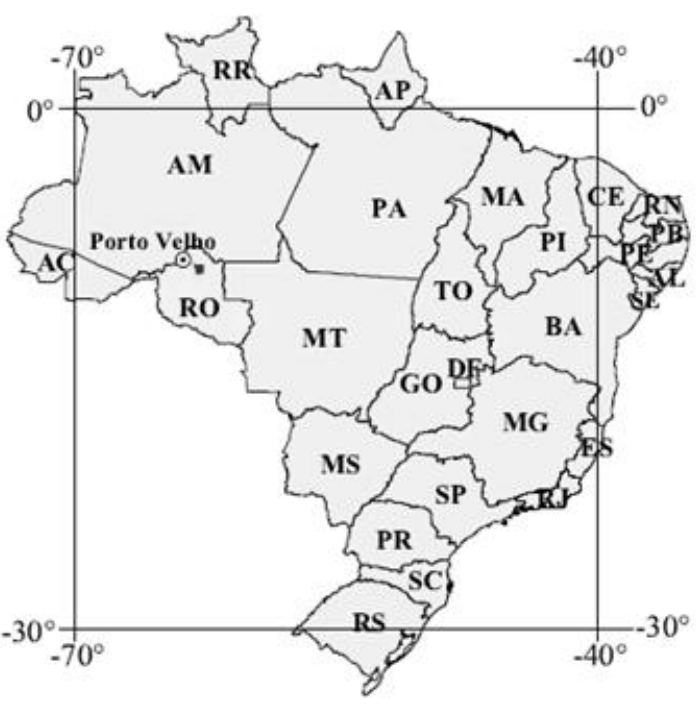

Decreto de Criação no 90224 de 25/09/1984

Área em Decreto: 215.000,00 ha

Área Georreferenciada: 223.06,27 ha 
As caracterizaçóes iniciais dos solos de piso de lavra e rejeito seco na área da Serra da Onça - FLONA/Jamari/RO, são para o piso de lavra: $\mathrm{pH}=4,0\left(\mathrm{CaCl}_{2}\right)$, matéria orgânica $=7,0 \mathrm{~g} \mathrm{dm}^{-3}$, fósforo $=4,0 \mathrm{~g} \mathrm{dm}^{-3}$, potássio $=0,5 \mathrm{mmol}_{c}$ $\mathrm{dm}^{-3}$, cálcio $=2,0 \mathrm{mmol}_{c} \mathrm{dm}^{-3}$, magnésio $=1,0 \mathrm{mmol}_{\mathrm{c}} \mathrm{dm}^{-3}$, $\mathrm{H}+\mathrm{Al}=21,0 \mathrm{mmol} \mathrm{dm}^{-3}$, soma de base $=3,2 \mathrm{mmol}_{\mathrm{c}} \mathrm{dm}^{-3}$, capacidade de troca catiônica $=18,0 \mathrm{mmol}_{\mathrm{c}} \mathrm{dm}^{-3}, \mathrm{~V} \%=$ $21,0 \mathrm{mmol}_{\mathrm{c}} \mathrm{dm}^{-3}$, areia $=223,0 \mathrm{~g} \mathrm{~kg}^{-1}$, silte $=448,0 \mathrm{~g} \mathrm{~kg}^{-1}$ e areia $=351,0 \mathrm{~g} \mathrm{~kg}^{-1}$. Para a área de deposiçấo de rejeito: $\mathrm{pH}=4,0\left(\mathrm{CaCl}_{2}\right)$, matéria orgânica $=7,0 \mathrm{~g} \mathrm{dm}^{-3}$, fósforo $=$ $2,0 \mathrm{~g} \mathrm{dm}^{-3}$, potássio $=0,3 \mathrm{mmol} \mathrm{dm}^{-3}$, cálcio $=1,0 \mathrm{mmol}$ c $\mathrm{dm}^{-3}$, magnésio $=1,0 \mathrm{mmol}_{\mathrm{c}} \mathrm{dm}^{-3}, \mathrm{H}+\mathrm{Al}=15,0 \mathrm{mmol}_{\mathrm{c}}$ $\mathrm{dm}^{-3}$, soma de base $=2,6 \mathrm{mmo}_{\mathrm{lc}} \mathrm{dm}^{-3}$, capacidade de troca catiônica $=18 \mathrm{mmol}_{\mathrm{c}} \mathrm{dm}^{-3}, \mathrm{~V} \%=18,0 \mathrm{mmol}_{c} \mathrm{dm}^{-3}$, areia $=$ $732,0 \mathrm{~g} \mathrm{~kg}^{-1}$, silte $=140,0 \mathrm{~g} \mathrm{~kg}^{-1}$ e areia $=124,0 \mathrm{~g} \mathrm{~kg}^{-1}$.

As análises de carbono e nitrogênio da biomassa microbiana foram realizadas de acordo com o método proposto por VANCE et al. (1987). A atividade da desidrogenase pelo método descrito em CASIDA et al. (1964). No tecido vegetal foram realizadas análises dos teores de: nitrogênio (SARRUge e HaAg, 1974; Vitti, 1988), fósforo (Sarruge e HaAg, 1974), potássio (SARruge e HaAg, 1974), cálcio e magnésio (Sarruge e HaAg, 1974), enxofre (VITTI, 1988), ferro, manganês, cobre e zinco (SARruge e HaAg, 1974)

Os resultados foram submetidos à análise de variância $(p<0,05)$ e, nos casos em que o teste $\mathrm{F}$ foi significativo, aplicou-se o teste Tukey para a comparação das médias (Banzatto e Kronka, 1992).

\section{RESULTADOS E DISCUSSÃO}

Em relação ao nitrogênio da biomassa microbiana (BMN) todas as amostras, nos diferentes tratamentos analisados, não diferiram entre si. Apenas nas amostras coletadas no solo de mata os valores foram superiores aos demais (Tabela 1). Assim, o BMN parece refletir o efeito da qualidade

Tabela 1. Nitrogênio e Carbono da biomassa microbiana em solo minerado após cultivo de leguminosas

\begin{tabular}{|c|c|c|}
\hline \multirow{2}{*}{ Tratamento } & \multicolumn{2}{|c|}{ Biomassa microbiana } \\
\hline & BMN & BMC \\
\hline & $\mathrm{mg} \mathrm{kg}^{-1}$ TFSE & $\mathrm{mg} \mathrm{kg}^{-1}$ TFSE \\
\hline T1 & $0,12^{\mathrm{A}}$ & $1090,81^{A B C}$ \\
\hline T2 & $1,54^{\mathrm{A}}$ & $880,87^{\mathrm{BCD}}$ \\
\hline T3 & $1,41^{\mathrm{A}}$ & $1344,25^{\mathrm{AB}}$ \\
\hline T4 & $1,33^{A}$ & $466,41^{D}$ \\
\hline T5 & $9,95^{\mathrm{B}}$ & $1514,42^{A}$ \\
\hline T6 & $0,89^{A}$ & $425,43^{D}$ \\
\hline T7 & $0,54^{\mathrm{A}}$ & $531,35^{\mathrm{D}}$ \\
\hline C.V. $(\%)$ & 28,11 & 29,08 \\
\hline
\end{tabular}

TFSE = terra fina seca em estudo.

$\mathrm{T} 1$ = piso de lavra com plantio de um ano; $\mathrm{T} 2$ = piso de lavra com plantio de dois anos; T3 = piso de lavra com plantio de três anos; T4 = rejeito com plantio de um ano; $\mathrm{T} 5$ = solo de mata; $\mathrm{T} 6$ = piso de lavra sem plantio e $\mathrm{T} 7$ = rejeito sem plantio. $\mathrm{Na}$ área de deposição de rejeito houve apenas um plantio.

Médias seguidas pela mesma letra, na coluna, não diferem significativamente entre si pelo teste Tuckey a $5 \%$. nutricional do material da superfície, no caso da mata, a serrapilheira, verificando-se a sequência decrescente de mata, piso de lavra com plantio de dois anos, piso de lavra com plantio de três anos, rejeito com plantio de um ano, rejeito sem plantio, piso de lavra sem plantio e piso de lavra com plantio de um ano. Para a vegetação nativa, vale ressaltar o predomínio de um bosque e sub-bosque instalados há bastante tempo, permitindo a formação de uma densa rede de raízes responsável por uma elevada ciclagem estimulando a atividade microbiana. Segundo Jenkinson e LADD, (1981) a biomassa microbiana do solo é definida como a parte viva da matéria orgânica excluindo-se raízes de plantas e restos animais maiores que $5 \times 10 \mathrm{~mm}^{3}$, contendo em média $2 \%$ a $5 \%$ do C total e $1 \%$ a $5 \%$ do $\mathrm{N}$-total do solo.

A decomposição da matéria orgânica depende da quantidade da serrapilheira, consequentemente da espécie em questấo, de parâmetros climáticos como a temperatura e a umidade, e das características físico-químicas do solo que influenciam diretamente a microbiota. Enquanto fatores climáticos parecem ter efeito pontual e apenas temporariamente inibitórios à atividade microbiana, a qualidade da serrapilheira parece ser decisiva para a composição da microfauna edáfica (Froufe, 1999). De maneira geral, as leguminosas que nodulam e fixam nitrogênio produzem serrapilheira de baixa relação $\mathrm{C} / \mathrm{N}$ o que facilita a decomposição (Reis et al., 2000).

Para o carbono da biomassa microbiana (BMC), os maiores valores foram constatados para mata, piso de lavra com plantio de um e três anos, os quais não tiveram diferenças significativas entre si (Tabela 3). ReIs et al. (2000), estudando o efeito do plantio de leguminosas arbóreas na recuperação de áreas degradadas sob a atividade microbiana do solo, observaram que os maiores valores de BMC foram verificados para a vegetação espontânea, seguida de acácia, eucalipto e consórcio que não diferiram entre si. Segundo Gama-Rodriques (1995), os valores de BMC indicam o potencial de reserva deste elemento que participa no processo de umidificaçáo, enquanto a biomassa microbiana do nitrogênio (BMN) estima a reserva de nitrogênio que poderá ser reabsorvido pelas plantas.

Assim, em relaçáo à biomassa microbiana observa-se que o plantio de leguminosas utilizadas para a adubaçáo verde proporcionou aumento significativo na BMC, principalmente, após três anos de plantio. Em relação à BMN, este plantio ainda não foi suficiente para promover alteraçôes no solo/substrato. CARneiro et al. (2008), estudando o C-orgânico, $\mathrm{N}$-total e biomassa microbiana em áreas de reabilitaçấo após a mineração de bauxita, observaram que o tempo de reabilitação é mais determinante que as espécies vegetais na recuperação dos teores de C-orgânico, $\mathrm{N}$-total e da biomassa microbiana no solo; estes atributos servem como indicadores das funçôes biológicas do solo. Os atributos da atividade biológica do solo sofrem grande impacto da mineração, mas a recuperação de suas funçôes ocorre com certa rapidez de um ano de reabilitaçáo das 
áreas estudadas. Chaer e Tótola (2007) concluíram que o nitrogênio da biomassa microbiana e a atividade das enzimas, dentre elas a desidrogenase, tiveram indicadores sensíveis em solos.

Em relação à atividade da desidrogenase, pode-se observar que o solo sob vegetação nativa proporcionou valores superiores diferindo significativamente dos demais tratamentos (Tabela 4). Os pisos de lavra com plantio de leguminosas no intervalo de tempo de 1, 2 e 3 anos (tratamentos T1, T2 e T3) não diferiram significativamente entre si. No entanto, os tratamentos "piso de lavra sem plantio" (T6) e o tratamento "rejeito arenoso sem plantio" (T7) juntamente com o tratamento "rejeito com um ano de plantio" (T4) foram os que tiveram a menor atividade da desidrogenase. Dessa forma, observa-se que para a atividade da desidrogenase o plantio de leguminosas promoveu aumento no tempo, porém, não diferiu entre os anos de plantio indicando que, provavelmente, mais alguns anos seriam necessários para que esta atividade se aproxime do valor verificado na mata. A desidrogenase é uma enzima que promove a oxidação de um substrato específico pela subtração do hidrogênio; segundo CERri et al. (1992), parece estar condicionada à quantidade de matéria orgânica decomponível e intimamente relacionada à biomassa quando fontes externas de $\mathrm{C}$ são adicionadas ao solo (TABATABAI, 1994). TeiXeIra (2004) observou que a atividade da desidrogenase foi o indicador mais sensível para medir as alteraçôes provocadas pela atividade da mineração na mesma área desse estudo, sendo possível detectar sua atividade mesmo na testemunha absoluta (solo degradado sem tratamento) o que não ocorreu com a biomassa microbiana. Essa afirmação está

Tabela 2. Hidrólise do FDA e atividade da desidrogenase em solo minerado após cultivo de leguminosas

\begin{tabular}{|c|c|c|}
\hline \multirow{2}{*}{ Tratamento } & Hidrólise do FDA & Atividade da desidrogenase \\
\hline & mg fluoresceína $\mathbf{g}^{-1}$ TFSE $\mathbf{h}^{-1}$ & mg TPF $\mathbf{g}^{-1}$ TFSE $24 \mathrm{~h}^{-1}$ \\
\hline $\mathrm{T} 1$ & $2,83^{A}$ & $10,56^{\mathrm{B}}$ \\
\hline $\mathrm{T} 2$ & $2,15^{A}$ & $7,56^{\mathrm{BCD}}$ \\
\hline T3 & $2,66^{A}$ & $9,08^{\mathrm{BC}}$ \\
\hline T4 & $4,38^{A}$ & $2,74^{\mathrm{CD}}$ \\
\hline T5 & $14,78^{\mathrm{B}}$ & $30,83^{A}$ \\
\hline T6 & $3,02^{\mathrm{A}}$ & $1,48^{\mathrm{D}}$ \\
\hline T7 & $2,57^{\mathrm{A}}$ & $1,16^{\mathrm{D}}$ \\
\hline C.V. $(\%)$ & 28,07 & 34,25 \\
\hline
\end{tabular}

$\mathrm{T} 1$ = piso de lavra com plantio de um ano; $\mathrm{T} 2$ = piso de lavra com plantio de dois anos; $\mathrm{T} 3$ = piso de lavra com plantio de três anos; $\mathrm{T} 4$ = rejeito com plantio de um ano; $\mathrm{T} 5$ = solo de mata; $\mathrm{T} 6$ = piso de lavra sem plantio e T7 = rejeito sem plantio. $\mathrm{Na}$ área de deposiçāo de rejeito houve apenas um plantio.

Médias seguidas pela mesma letra, na coluna, não diferem significativamente entre si pelo teste Tuckey a $5 \%$.

Tabela 3. Nitrogênio, fósforo, enxofre, potássio e massa de matéria seca referentes às análises do tecido vegetal de leguminosas coletadas nas áreas de plantio

\begin{tabular}{|c|c|c|c|c|c|}
\hline \multirow{2}{*}{ Tratamento } & Nitrogênio & Fósforo & Enxofre & Potássio & Massa de matéria seca \\
\hline & \multicolumn{4}{|c|}{$\mathrm{mg} \mathrm{g}^{-1}$} & kg ha-1 \\
\hline $\mathrm{T} 1$ & $7,87^{\mathrm{A}}$ & $0,38^{A}$ & $1,10^{A}$ & $4,25^{\mathrm{AB}}$ & $4443,0^{A}$ \\
\hline $\mathrm{T} 2$ & $10,46^{A}$ & $0,32^{A}$ & $1,38^{\mathrm{A}}$ & $3,44^{\mathrm{A}}$ & $8337,0^{\mathrm{BC}}$ \\
\hline T3 & $19,84^{\mathrm{B}}$ & $1,25^{\mathrm{B}}$ & $1,37^{A}$ & $4,75^{\mathrm{BC}}$ & $10226,25^{c}$ \\
\hline T4 & $18,79^{\mathrm{B}}$ & $1,11^{\mathrm{B}}$ & $1,29^{A}$ & $5,88^{c}$ & $5511,0^{\mathrm{AB}}$ \\
\hline T5 & $15,50^{\mathrm{B}}$ & $0,43^{A}$ & $1,33^{A}$ & $0,66^{\mathrm{D}}$ & $6720,25^{\mathrm{ABC}}$ \\
\hline C.V. $(\%)$ & 15,34 & 16,05 & 16,42 & 13,87 & 23,25 \\
\hline
\end{tabular}

$\mathrm{T} 1$ = piso de lavra com plantio de um ano; T2 = piso de lavra com plantio de dois anos; T3 = piso de lavra com plantio de três anos; T4 = rejeito com plantio de um ano; T5 = solo de mata; plantio. Na área de deposição de rejeito houve apenas um plantio.

Médias seguidas pela mesma letra, na coluna, não diferem significativamente entre si pelo teste Tuckey a 5\%.

Tabela 4. Cobre, ferro, manganês, zinco, cálcio e magnésio referentes às análises do tecido vegetal de leguminosas coletadas nas áreas de plantio

\begin{tabular}{|c|c|c|c|c|c|c|}
\hline \multirow{2}{*}{ Tratamento } & Cobre & Ferro & Manganês & Zinco & Cálcio & Magnésio \\
\hline & \multicolumn{6}{|c|}{$\mathrm{mg} \mathrm{kg}^{-1}$} \\
\hline T1 & $3,94^{A}$ & $494,68^{A}$ & $15,31^{\mathrm{A}}$ & $15,31^{A}$ & $7,72^{\mathrm{A}}$ & $1,97^{A}$ \\
\hline T2 & $3,18^{A}$ & $550,34^{\mathrm{AC}}$ & $26,45^{\mathrm{BC}}$ & $26,45^{\mathrm{B}}$ & $8,33^{A}$ & $2,14^{\mathrm{A}}$ \\
\hline T3 & $2,84^{\mathrm{A}}$ & $547,52^{\mathrm{AC}}$ & $19,70^{C}$ & $19,70^{\mathrm{AB}}$ & $10,33^{\text {в }}$ & $2,51^{\mathrm{A}}$ \\
\hline T4 & $4,31^{\mathrm{A}}$ & $103,93^{B}$ & $20,93^{\mathrm{AB}}$ & $20,93^{\mathrm{AB}}$ & $7,86^{A}$ & $2,33^{A}$ \\
\hline T5 & $7,91^{\mathrm{B}}$ & $615,93^{c}$ & $24,29^{D}$ & $24,25^{\mathrm{AB}}$ & $4,80^{C}$ & $2,51^{\mathrm{A}}$ \\
\hline C.V. (\%) & 19,42 & 10,06 & 21,23 & 21,23 & 11,63 & 15,62 \\
\hline
\end{tabular}

$\mathrm{T} 1$ = piso de lavra com plantio de um ano; T2 = piso de lavra com plantio de dois anos; $\mathrm{T} 3$ = piso de lavra com plantio de três anos; T4 = rejeito com plantio de um ano; T5 = solo de mata; $\mathrm{Na}$ área de deposiçáo de rejeito houve apenas um plantio.

Médias seguidas pela mesma letra, na coluna, não diferem significativamente entre si pelo teste Tuckey a $5 \%$. 
de acordo com os dados apresentados na Tabela 1, sendo que os tratamentos T4, T6 e T7 apresentaram os menores valores para atividade da desidrogenase e não diferiram significativamente entre si.

Em trabalho realizado na mesma área TeIXeIra (2004) observou que a atividade da desidrogenase foi um indicador mais sensível do que a biomassa microbiana para aferir sobre alterações em solos degradados.

Para a hidrólise do diacetato (FDA), apenas no solo de mata os valores diferiram significativamente dos demais, ou seja, os tratamentos não tiveram diferenças significativas entre si (Tabela 2). CARNEIRo et al. (2008) observaram que a hidrólise do diacetato (FDA) aumenta rapidamente após a reabilitação de uma área minerada por bauxita, com valores similares no campo, na serra e nas áreas em reabilitação após um ano, resultados que contrapóem aos verificados neste trabalho.

Os maiores valores de matéria seca (Tabela 3) foram obtidos nessa ordem: piso de lavra com plantio de três anos, piso de lavra com plantio de dois anos e na serrapilheira; esses valores não diferiram significativamente entre si, indicando que a produção de matéria seca nas áreas de plantio, principalmente no piso de lavra, se assemelham ao constatado na mata (serrapilheira), o que demonstra avanço no programa de recuperação da área.

Segundo Longo et al. (2005), nas áreas degradadas estudadas (piso de lavra e rejeito seco) ocorreram diferenças entre elas, principalmente em relação aos parâmetros físico-químicos do solo; assim, além da análise do tipo de cobertura vegetal implantado, o tipo de material no qual se procederam os trabalhos também influenciou de forma direta nas mudanças ocorridas no solo. Dessa forma, quando se pretende desenvolver projetos de recuperação dessas áreas, a recuperaçáo do solo/substrato deve ser priorizada para o sucesso do empreendimento e as áreas em situaçóes degradadas devem ser trabalhadas de forma diferenciadas.

Em relação ao nitrogênio, os maiores valores foram verificados nas amostras coletadas no piso de lavra com três anos de plantio (T3) $\left(19,84 \mathrm{mg} \mathrm{g}^{-1}\right)$ seguido pelo rejeito com plantio de um ano (T4) e mata (T5); verificou-se que esses tratamentos não diferiram entre si. Os teores de fósforo foram mais elevados nos tratamentos T3 e T4 (1,25 e 1,14 $\mathrm{mg} \mathrm{g}^{-1}$ respectivamente), sendo significativamente superiores aos demais, inclusive quando comparados ao solo de mata. Esse efeito, provavelmente, foi provocado pela própria adubação à qual as leguminosas foram submetidas por ocasião do plantio.

Os teores de $\mathrm{K}$ também foram mais elevados nos tratamentos T4 e T3 (5,88 e 4,75 $\mathrm{mg} \mathrm{g}^{-1}$ respectivamente), sendo superiores aos valores constatados no material coletado na mata, comportamento similar também foi observado para o Ca (Tabela 4). Os teores de magnésio e enxofre não diferiram entre si. Longo et al. (2005), em estudos realizados nos solos dessas áreas, observaram que o processo de extração de cassiterita promoveu alteraçôes significativas, e os parâmetros como o $\mathrm{pH}$, teores de matéria orgânica, $\mathrm{P}, \mathrm{K}, \mathrm{V} \%$, CTC, $\mathrm{H}+\mathrm{Al}$ foram os mais alterados pelo processo de supressão da vegetação original e extração do minério.

Em relação aos teores de micronutrientes (Tabela 4), os valores mais elevados de cobre e ferro foram verificados na mata; os teores de zinco praticamente não diferiram entre os tratamentos e os teores de manganês foram superiores aos valores observados na mata.

Dessa maneira, observa-se que, em relação à absorção dos nutrientes e à produção de matéria seca, a adubação realizada por ocasião do plantio de leguminosas foi eficiente para suprir as necessidades dos vegetais analisados (P, Ca, K e matéria seca).

\section{CONCLUSÕES}

1. O uso de indicadores biológicos como o carbono e o nitrogênio da biomassa microbiana (BMC e BMN respectivamente), na avaliaçáo das estratégias de recuperação do solo adotadas, revela que o plantio de leguminosas e sua posterior incorporação vem promovendo alteraçôes graduais na ativação biológica dos solos.

2. A atividade de desidrogenase, sensível às açôes aplicadas, revela alteraçóes positivas na atividade biológica do solo.

\section{AGRADECIMENTOS}

À Fundação de Amparo à Pesquisa do Estado de São Paulo (FAPESP), a Brascan Brasil e ao Instituto Brasileiro do Meio Ambiente e Recursos Minerais Renováveis (IBAMA).

\section{REFERÊNCIAS}

ANDERSON, T.H.; DOMSCH, K.H. The metabolic quocient for $\mathrm{CO}_{2}\left(\mathrm{qCO}_{2}\right)$ as a specific activity parameter to assess the effects of environmental condictions, such as $\mathrm{pH}$, on the microbial biomass of forest soils. Soil Biology and Biochemistry, v.25, p.393-395, 1993.

BANZATTO, D.A.; KRONKA, S.N. Experimentação agrícola. 2.ed. Jaboticabal: Funep, 1992. 247p.

BENDING, G.D.; TURNER, M.K.; RAYNS, F.; MARX, M.C.; WOOD, M. Microbial and biochemical soil quality indicators and their potential for differentiating areas under constrating agricultural management regimes. Soil Biology and Biochemistry, v.36, p.1785-1792, 2004.

CARNEIRO, M.A.C.; SIQUEIRA, J.O.; MOREIRA, F.M.S.; SOARES, L.L. Carbono orgânico, nitrogênio total, biomassa 
e atividade microbiana do solo em duas cronossequências de reabilitação após a mineração de bauxita. Revista Brasileira de Ciência do Solo, v.12, p. 621-632, 2008.

CASIDA, L.E.; KLEIN, D.A.; SANTORO, T.S. Soil dehydrogenasase activity. In: WEARVER R.W. et al. (Ed.). Methods of soil analysis: microbilogical and biochemical properties. Madison: ASA/SSA, 1964. p. 775-883.

CERRI, C.C.; ANDREAU, F.; EDUARDO, B.P.O. Ciclo do carbono no solo. In: CARDOSO, E.J.B.N., TSAI, S.M., NEVES, M.C.P. Microbiologia do solo. Campinas: Sociedade Brasileira de Ciência do Solo, 1992. 360p.

CHAER, G.M.; T'TOLA, M.R. Impacto do manejo de resíduos orgânicos durante a reforma de plantios de eucalipto sobre indicadores de qualidade de solo. Revista Brasileira de Ciência do Solo, v.31, p. 1381-1396, 2007.

EMBRAPA. Centro Nacional de Pesquisa de Solos. Sistema brasileiro de classificação de solos. Brasília: Embrapa Produção de Informação; Rio de Janeiro: Embrapa Solos, 1999. 412p.

FRANCO, A.A.; CAMPELO, E.F.C.; DIAS, L.E.; FARIA, S.M. Revegetação de solos degradados. Seropédica: EMBRAPA-CNPBS, 1992, 8p. (EMBRAPA-CNPBS. Comunicado Técnico, 9)

FROUFE, L.C.M. Decomposição de serrapilheira e aporte de nutrientes em plantios puros e consorciados de Eucalyptus grandis Hill ex. Maiden e duas leguminosas fixadoras de $\mathrm{N}_{2}$ (Pseudosamanea guachapele Dugand e Acácia mangium Willd). 1999, 110p. Dissertação (Mestrado) - Universidade Federal Rural do Rio de Janeiro, Seropédica.

GAMA-RODRIGUES, E.F.; GAMA-RODRIGUES, A.C.; BARROS, N.F. Biomassa microbiana de carbono e nitrogênio de solos sob diferentes coberturas florestais. Revista Brasileira de Ciência do Solo, v.21, p.361-365, 1997.

GRISI, B.M.; SANTOS, O.M. Respiração edáfica em vegetação natural e submetida à queima, num ecossistema de floresta tropical no sul da Bahia. Revista Brasileira de Biologia, v.38, p. 579-586, 1999.

JENKINSON, D.S.; LADD, J.N. Microbial biomass in soil: measurement and turnover. In: PAUL, E.A., LADD, J.N. (Ed.). Soil Biochemistry, v.5, p.415-471, 1981.

LEIRÓS, M.C.; TRASAR-CEPEDA, C.; SEOANE, S.; GILSOTRES, F. Biochemical properties of acid soils under clímax vegetation (Atlantic oakwood) in na área of the Europea. Soil Biology and Biochemistry, v.32, p.733-745, 2000.

LONGO, R.M.; RIBEIRO, A.I.; MELO, W.J. Caracterização física e química de áreas mineradas pela extração de cassiterita. Bragantia, v.64, p.101-107, 2005.
PFENNING, L.; EDUARDO, B.P.; CERRI, C.C. Os métodos de fumigação-incubação e fumigação-extração na estimativa de solos da Amazônia. Revista Brasileira de Ciência do Solo, v.16, p. 31-37, 1992.

RADAMBRASIL. Folha SC-20. Porto Velho. Rio de Janeiro: Departamento Nacional de Produção Mineral, 1978. 661p. (Levantamento de Recursos Naturais, 16)

RESENDE, A.V., KONDO, M.K. Leguminosas e recuperação de áreas degradadas. Informe Agropecuário, v.22, p. 46-56, 2001.

REIS, L.L.; CAMPELLO, E.F.; FRANCO, A.A. Atividade microbiana de um planosssolo sob plantio de leguminosas arbóreas utilizadas na recuperação de áreas degradadas em comparaçáo ao eucalipto e vegetação espontânea. In: Simpósio Nacional de Recuperação de Áreas Degradadas, 4., 2000, Blumenau. Anais.... 2000 (Cd-Rom)

SARCEPEDA, C.; LEIRÓS, C.; GIL-SOTRES, F.; SEOANE, S. Towards a biochemical quality index for soil: An expression relating several biological and biochemical properties. Biology and Fertility of Soils, v.26, p.100-106, 1998.

SARRUGE, J.R.; HAAG, H.P. Análises químicas em plantas. Piracicaba: ESALQ/USP, 1974. 56 p.

TABATABAI, M.A. Soil enzymes. In: WEAVER, R.W. (Ed.). Methods of soil analysis: microbiological and biochemical properties. Madison: ASA/SSA, 1994. p.775-883.

TEIXEIRA, T.T. Aplicação de lodo de estação de tratamento de água em solo degradado por mineração de cassiterita. 2004. 85p. Tese (Doutorado - Curso de Agronomia) - FCAV/UNESP, Jaboticabal.

TRASAR-CEPEDA， C.; LEIRÓS， C.; GIL-SOTRES， F.; SEOANE, S. Towards a biochemical quality index for soils: $\mathrm{Na}$ expression relating several biological in biociochemical properties. Biology and Fertility of Soils, v. 26, p. 100-106, 1998.

VANCE, E.D.; BROOKES, P.C.; JENKINSON, D.S. An extraction method for measurement soil microbial biomass C. Soil Biology and Biochemistry, v.19, p.703-707, 1987.

VITTI, G.C. Avaliação e interpretação do enxofre no solo e em planta. Jaboticabal: FUNEP, 1988. 37p.

WRANDLE, E.D., BROOKES, P.C., JENKINSON, A.S. Na extraction method for measuring soil microbial biomass C. Soil Biology and Biochemistry, v.19, p.703-707, 1992.

WUTKE, E.B. Adubação verde: manejo da fitomassa e espécies utilizadas no Estado de São Paulo. In: CURSO SOBRE ADUBAÇÃO VERDE NO INSTITUTO AGRONÔMICO DE CAMPINAS, 1993, Campinas. Anais:... Campinas: Instituto Agronômico, 1993. p.17-29. 